\title{
CHEMICAL KINETICS OF HYDROGEN SULFIDE SELECTIVE OXIDATION IN IRON CHELATE SOLUTIONS
}

\author{
O.G. TSAPEKIS \\ C.E. SALMAS \\ G.P. ANDROUTSOPOULOS *
}

Received: $11 / 10 / 07$

Accepted: 02/04/08

\author{
School of Chemical Engineering, \\ Chemical Process Engineering Laboratory \\ National Technical University of Athens \\ 9 Heroon Polytechniou Street, GR 15780, Athens Greece
}

*to whom all correspondence should be addressed: e-mail: androuts @chemeng.ntua.gr

\begin{abstract}
The present work concerns the investigation of the chemical kinetics of $\mathrm{H}_{2} \mathrm{~S}$ selective oxidation into elemental sulfur, by gas absorption and chemical reaction in $\mathrm{Fe}^{3+}$.(NTA) aqueous solutions. By using initial reactivity data, priority is given to the study of intrinsic kinetics i.e. to avoid interactions with ligand degradation and the presence of sulfur. A wetted wall gas-liquid reactor was employed under a batch-recycle regime. The conversion of $\mathrm{Fe}^{3+}$ to $\mathrm{Fe}^{2+}$ chelate was determined over the $\mathrm{pH}$ range ca. 3-6, temperature range ca. $30-60^{\circ} \mathrm{C}$ and a short overall per run contact time of phases. The penetration theory was used for the evaluation of intrinsic reaction rate constant and enhancement factor. Activation energy values determined from the pertinent Arrhenius plots fall in the range, Ea=17.2- $22.8 \mathrm{kcal}$ $\mathrm{mol}^{-1}$. These values compare satisfactorily with the value Ea=24 kcal mol${ }^{-1}$ obtained from a similar kinetic study performed in a bubble column reactor and indicates a chemical reaction control of the overall gas absorption phenomenon. Enhancement factors varied in the respective ranges $\mathrm{E}=2.7-7.5(\mathrm{pH}=3), \mathrm{E}=3.2-14.1(\mathrm{pH}=4), \mathrm{E}=5.9-17.0(\mathrm{pH}=5), \mathrm{ka} \mathrm{I}=6.7-$ $20.1(\mathrm{pH}=6)$ indicating a substantial increase of the mass transfer coefficient due to chemical reaction. For the experimental conditions applied in this study the following kinetic correlation was validated:
\end{abstract}

$$
R_{H 2 S}=\left\{[-10.62+4.15(p H)] \cdot 10^{14} \exp \left(-19083 / R_{g} T\right)\right\} C_{H 2 S}
$$

KEYWORDS: hydrogen sulfide, selective oxidation, iron chelate, absorption with chemical reaction, NTA, nitrilo triacetic acid.

\section{INTRODUCTION}

Given that a variety of sulfur compounds are found in solid, liquid and gas fossil fuels, (Speight, 1990; Smith et al., 1994) hydrogen sulfide is a regular component of gaseous streams of fuels conversion and upgrading processes i.e. liquid fuels hydrodesulphurization, coal gasification, etc. It is also met in biogas, natural gas and geothermal fluids. The separation of $\mathrm{H}_{2} \mathrm{~S}$ from these streams is absolutely necessary prior to its conversion into sulfur or other useful products due to its odor, toxicity and corrosive properties. Removal of $\mathrm{H}_{2} \mathrm{~S}$ from the said streams is also required before using them either as fuels or as reactants for the synthesis of chemicals. Historically, various methods for hydrogen sulfide separation from gaseous mixtures and conversion to sulfur have been developed. The most important, industrially established methods belong to a family of processes combining $\mathrm{H}_{2} \mathrm{~S}$ removal by absorption in alkalonamine solutions and Claus sulfur recovery variants. The amine plant is made up of a chemical absorption column (tray or packed bed tower) and an amine regeneration column (sripper). The selection of the appropriate amine or amines mixture depends on $\mathrm{H}_{2} \mathrm{~S}$ absorption selectivity in the presence of other acidic gas components (e.g. $\mathrm{CO}_{2}$ ). In the Claus process furnace one third of the $\mathrm{H}_{2} \mathrm{~S}$ contained in the stripper effluent gas 
stream is combusted to $\mathrm{SO}_{2}$ and reacts with the unconverted $\mathrm{H}_{2} \mathrm{~S}$ to yield $\mathrm{S}$ according to the reaction $\mathrm{SO}_{2}+2 \mathrm{H}_{2} \mathrm{~S}=2 \mathrm{H}_{2} \mathrm{O}+3 \mathrm{~S}$ (thermal stage). Sulfur is further recovered in down stream catalytic stages including sulfur separation units. An extensive account of these processes and numerous literature sources are found in Kohl and Nielsen (1997).

Another important family of methods encompasses those based on the selective oxidation of $\mathrm{H}_{2} \mathrm{~S}$ into elemental sulfur ín aqueous solutions of iron chelates or other oxidative agents, (i.e. redox methods). A brief review related to the development of new methods for sulfur recovery from gas streams is given by Garuana (1996), Hardison (1985) and Kohl and Nielsen (1997). The most important advantages of the redox methods are (i) the mild reaction temperatures (e.g. $20-60{ }^{\circ} \mathrm{C}$ ), (ii) $\mathrm{H}_{2} \mathrm{~S}$ conversion is practically complete (99.99\%) and occurs ín a single step, (iii) the use of air as oxidant for the regeneration of the oxidative solution. A possible drawback of these methods is the increased cost of chemicals, especially when high consumption of reactants is required due to low selectivity or decomposition of the chelating agent. In any case, the choice of the desulfurization method, for a specific application, depends on the technical features and process economics. A comparative economic study reported by Heisel, and Marold (1987) concludes that gas streams with high flow rates $\left(>10^{3}\right.$ $\mathrm{Nm}^{3} \mathrm{~h}^{-1}$ ) and high $\mathrm{H}_{2} \mathrm{~S}$ concentration $(>10$ vol \%) are usually treated with a conventional absorption process followed by the Claus process. It is also suggested that the Sulfolin process, taken as being a typical liquid $\mathrm{H}_{2} \mathrm{~S}$ redox representative, is to be preferred when compared with the absorption-Claus system for low $\mathrm{H}_{2} \mathrm{~S}$ concentrations $(<10 \mathrm{vol} \%)$ and feed flow rates up to $10^{5} \mathrm{Nm}^{3} \mathrm{~h}^{-1}$ or for a wide $\mathrm{H}_{2} \mathrm{~S}$ concentration range (0-100 vol. \%) but low feed rate $\left(\sim 200 \mathrm{Nm}^{3} \mathrm{~h}^{-1}\right)$.

At least two industrially applied processes for the selective oxidation of $\mathrm{H}_{2} \mathrm{~S}$ into elemental sulfur using solutions of $\mathrm{Fe}^{3+}$ are cited in the literature (Kohl and Nielsen, 1997). The first bears the commercial name Lo-cat (Air Resources Inc.; Bedell et al., 1988), takes place ín aqueous solutions of a $\mathrm{Fe}^{3+}$ complex with a proprietary agent i.e. ARI-30 and the regeneration is accomplished by blowing air through the solution. The operating conditions of the Lo-cat method are as follows: $\mathrm{pH}=8.0-8.5$, temperature $4-50{ }^{\circ} \mathrm{C}$, low pressure (i.e atmospheric $\sim 0.5$ $\mathrm{MPa}$ ) is recommended for the processing of streams containing a $\mathrm{H}_{2} \mathrm{~S}$ percentage higher than $5 \%$, iron concentration 500-2000 ppm, sulfur production capacity 1-5 Itn $\mathrm{d}^{-1}(1 \mathrm{lth}=1016 \mathrm{~kg})$. The second commercial process for the oxidation of $\mathrm{H}_{2} \mathrm{~S}$ in aqueous solutions of iron chelates is named SulFerox (Sherwood et al., 1975), operates economically ín stable solutions of an iron chelate of $4 \%$ concentration, pressures up to $1.5-2.0 \mathrm{MPa}$ and high temperatures that are not noted by number. A commercial application of this method is the desulphurization of natural gas (Bedell et al., 1988; Chevron U.S.A. Production Co., 1996).

According to Hua et al. (2001) the $\mathrm{Fe}^{3+} / \mathrm{Fe}^{2+}$ chelate systems, particularly the $\mathrm{Fe}^{3+} / \mathrm{Fe}^{2+} \mathrm{NTA}$ processes, are now replacing those based on $\mathrm{As}^{5+} / \mathrm{As}^{3+}$ (Grimmarco-Vetrocoke process) and $\mathrm{V}^{5+} \mathrm{N}^{4+}$ (Stretford process) redox couples. Even the dominant iron chelate methods (e.g. $\mathrm{Fe}^{3+} / \mathrm{Fe}^{2+} \mathrm{NTA}$ ) are not free of operating problems especially due to ligand (chelate) oxidative degradation. A proposed mechanism to explain the degradation of Fe-NTA involves the presence of ferrous complex with strongly oxidizing intermediates e.g. $\mathrm{OH}$.and $\mathrm{H}_{2} \mathrm{O}_{2}$. Considerable slowing down of the undesired ligand decomposition process is achieved by addition of reagents (e.g. sodium thiosulfate) that act as scavengers for the hydroxyl radicals. Research is also directed to the synthesis and evaluation of new, resistant to degradation, Fecomplexes e.g. phosphorous containing ligands e.g. NTA.3P (Nitrilo-trimethylenephosphonic acid), and even further to the use of Thiobacillus ferrooxidans cultures to accelerate the ferrous oxidation reaction and thus overcoming the use of organic ligands or to reduce ligands degradation (Hua et al., 2005; Pagella and De Faveri, 2000).

The majority of the research results referred to the oxidation of $\mathrm{H}_{2} \mathrm{~S}$ with $\mathrm{Fe}^{3+}(\mathrm{NTA})$ are not published in the open literature. Because of the special significance, the chemistry of the complex compounds involved is patented. Regarding the use of the NTA (NitriloTriacetic Acid) in the oxidation of $\mathrm{H}_{2} \mathrm{~S}$ into elemental sulfur, Neumann and Lynn (1984) studied absorption with chemical reaction of $\mathrm{H}_{2} \mathrm{~S}$ in an aqueous solution of $\mathrm{Fe}^{3+}(\mathrm{NTA})$ using a continuous flow, wetted wall column operated at steady state. Absorption runs were carried out ín a narrow temperature (i.e. $60-65^{\circ} \mathrm{C}$ ) and $\mathrm{pH}$ (i.e. $3.5-4.5$ ) range. In the latter research work it was 
concluded that liquid phase mass transfer controls the overall process which can be characterized as "absorption with instantaneous chemical reaction".

Demmink et al. (1994), carried out a similar investigation using a co-current down flow column packed reactor, equipped with static mixers (type SMV-4) and operated in a semi-batch mode, i.e. continuous with respect to the gas phase and batch-recycle with respect to the liquid phase. They reported that the reaction of $\mathrm{H}_{2} \mathrm{~S}$ with $\mathrm{Fe}^{3+}(\mathrm{NTA})$ solution proceeds at a finite rate and is first order with respect to each reactants separately, a result contrasting that of Neumann and Lynn (1984). However, it should be noted that in the work of Demmink et al. oxidation was performed at $13{ }^{\circ} \mathrm{C}$ and $\mathrm{pH}=6.7-8.2$. These conditions are quite close to those of industrial methods. Hydrogen sulfide oxidation results in $\mathrm{Fe}^{3+}$ (NTA) aqueous solutions using a bubble column laboratory reactor, was reported by Pitsinis and Androutsopoulos (1997). Absorption runs were carried out in the temperature range $\mathrm{T}=36-63^{\circ} \mathrm{C}$ and $\mathrm{pH}=3.6-$ 6.5 and the application of the two films theory confirmed a chemical reaction control of the gas absorption phenomenon. A first order kinetic with respect to $\mathrm{H}_{2} \mathrm{~S}$ concentration and zero order with respect to $\mathrm{Fe}^{3+}(\mathrm{NTA})$ were deduced and an activation energy $\mathrm{Ea}=24 \mathrm{kcal} \mathrm{mol}^{-1}$, was obtained.

In the present work the results are reported, of a kinetic study for the selective oxidation of $\mathrm{H}_{2} \mathrm{~S}$ in aqueous $\mathrm{Fe}^{3+}$ (NTA) using a wetted wall column reactor under temperature, $\mathrm{pH}$ and iron chelate concentration comparable to those applied in the study reported by Pitsinis and Androutsopoulos (1997). Particular care was taken for $\mathrm{pH}$ stabilization using appropriate buffering of acetic acid-sodium acetate solutions during a specified $\mathrm{H}_{2} \mathrm{~S}$ oxidation procedure. The scope of the present work is to confirm the presence of a finite reaction kinetic rate and to figure out the effect of temperature, concentration and $\mathrm{pH}$ upon the reaction rate constant. The selection of a wetted wall column reactor ensures a reliable evaluation of the specific interfacial area. The operation contact time of phases was kept below 20 min or $\mathrm{Fe}^{3+}$ conversion below $30 \%$, to minimize the influence of sulfur on gas absorption and the chelate degradation side effects. The penetration theory, for gas absorption with chemical reaction, is being used for interpreting the experimental data. The investigation of the intrinsic phenomena controlling reaction kinetics is very important since such information allow for the development of an improved design of the pertinent industrial processes. It is of particularly significance for the choice of the process specifications i.e. composition and concentration of the chelating agent, operating conditions (temperature, pressure, $\mathrm{pH}$, stirring, etc.) and finally the development of the overall process flow sheet.

\section{METHOD \\ Materials}

Gases: Commercial grades of $\mathrm{N}_{2}$ and $\mathrm{H}_{2} \mathrm{~S}$ in pressure cylinders were supplied by L' Air Liquid Hellas. Reagent (Merck products): $\mathrm{FeCl}_{3} \cdot 6 \mathrm{H}_{2} \mathrm{O}$ (99.0-102.0 \%, MW $=270.33$ ), NTA (Nitrilotriacetic acid, $\mathrm{N}\left(\mathrm{CH}_{2} \mathrm{COOH}\right)_{3}$, purity $\geq 99 \%$, MW: 191.14), $\mathrm{NaOH}$ (purity $\geq 99 \%$ ) $\mathrm{CH}_{3} \mathrm{COOH}$ (standard $0.25 \mathrm{M}$ ), $\mathrm{Na}_{2} \mathrm{~S}_{2} \mathrm{O}_{3}$ (standard solution, $0.1 \mathrm{M}$ ), $\mathrm{KJ}, \mathrm{KCl}$ (solution $3 \mathrm{M}$ ), $\mathrm{KCl}$ (purity $\geq$ $99.5 \%) \mathrm{H}_{2} \mathrm{SO}_{4} 98 \%$ w/w), de-ionised water was used for dissolution of chemicals.

\section{Preparation of $\mathrm{Fe}^{+3} \cdot \mathrm{NTA}$ solution and $\mathrm{pH}$ control}

To prepare $1.0 \mathrm{It}$ of aqueous iron chelate solution, (the amount regularly charged in the recycle reactor tank was about $2 \mathrm{It}$ ), of initial chelate concentration $\mathrm{C}_{\text {chelate (0) }}=0.1 \mathrm{M}, 27.06 \mathrm{~g}$ $(0.10 \mathrm{~mol})$ of $\mathrm{FeCl}_{3} \cdot 6 \mathrm{H}_{2} \mathrm{O}$ and $21.18 \mathrm{~g}(0.1109 \mathrm{~mol})$ of NTA, are dissolved in $1.0 \mathrm{I}$ of $\mathrm{CH}_{3} \mathrm{COOH} 0.25 \mathrm{M}$ aqueous solution under intensive stirring until complete solids dissolution. Then, $\mathrm{NaOH}$ is added until the desired $\mathrm{pH}$ value is obtained. $\mathrm{A} \mathrm{pH}$-meter is used for regular $\mathrm{pH}$ monitoring. The $\mathrm{pH}$-meter membrane is preserved in a $3 \mathrm{M} \mathrm{KCl}$ solution, (Microprocessor pH Meter, Ph 95, WTW).

\section{Determination of $\mathrm{Fe}^{+3}$ concentration}

A typical $\mathrm{C}_{\mathrm{Fe} 3+}$ determination is as follows: in $3 \mathrm{ml}$ iron chelate solution, we add $30 \mathrm{ml} \mathrm{H}_{2} \mathrm{SO}_{4}$ solution $\left(15 \%\right.$ vol. \%) and dissolve an amount of $\mathrm{KJ}$ (i.e. $\mathrm{KJ} \rightarrow \mathrm{K}^{+1}+\mathrm{J}^{-1}$ ) in excess of that required for complete reduction of ferric ions and $\mathrm{J}_{2}$ formation $\left(2 \mathrm{Fe}^{3+}+2 \mathrm{~J}^{-1} \rightarrow \mathrm{J}_{2}+2 \mathrm{Fe}^{2+}\right)$. The mixture is allowed for at least 10 min to react, so that the $\mathrm{Fe}^{+3}$ is entirely released from the 
chelate cation, $\left(\mathrm{Fe}^{3+} \cdot \mathrm{NTA} \rightarrow \mathrm{Fe}^{3+} \cdot+\mathrm{NTA}\right)$ due to $\mathrm{H}_{2} \mathrm{SO}_{4}$ action. Titration with a standard $\mathrm{Na}_{2} \mathrm{~S}_{2} \mathrm{O}_{3}$ solution enables the determination of $\mathrm{J}_{2}$ concentration and hence $\mathrm{C}_{\mathrm{Fe} 3+}$ is deduced. Each $\mathrm{C}_{\mathrm{Fe} 3+\mathrm{NTA}(\mathrm{t})}$ determination represents the mean of three values obtained by titrating three samples taken at a specified absorption time $t$.

\section{Gas flow measurement}

A rotameter (tapered vertical tube containing a float), equipped with a flow control valve and calibrated over the flow range $\left(5-25 \mathrm{ml} \mathrm{s}^{-1}\right)$ was employed for $\mathrm{N}_{2}$ feed flow control and measurement, $\left(0-8000 \mathrm{ml} \mathrm{min}^{-1}\right.$, AALBORG). Calibration straight line $Y=7.81478+1.12987 \mathrm{X}$, where [Y: 0-16, soap film positive displacement (sfpd) flow meter indication] and [X: 7-25 ml s${ }^{-1}$, $\mathrm{N}_{2}$ flow rate. Hydrogen sulfide feed flow was regulated via a manual flow control valve and a (sfpd) flow meter was employed for regular flow monitoring.

\section{Liquid recirculation}

A diaphragm dosing pump reciprocated pump, calibrated in the flow range $0.5-4.0 \mathrm{ml} \mathrm{s}^{-1}$ (pump indication $Y$ [0-2.6] vs liquid flow rate $X$ [0.5-4.0]: $Y=0.91675-2.04091 X+4.94596$ $X^{2}-4.5746 X^{3}+2.05279 X^{4}-0.43815 X^{5}+0.03576 X^{6}$ ) enabled the steady flow recirculation of the iron chelate solution from the tank to reactor inlet, (pump specifications: 10 bar max $P$, capacity at 10 bar $2.6 \mathrm{I} \mathrm{min}^{-1}, 138$ strokes $\mathrm{min}^{-1}$, motor power $74 \mathrm{~W}$ ). The return of the liquid from the reactor exit to the tank was done by gravity.

\section{Liquid heating-agitation and temperature monitoring}

Liquid phase heating and mixing is carried out in the liquid collection vessel (storage tank) which is part of the recycle loop by means of a Magnetic Stirrer-Heater equipped with a temperature on/off controller (MSH: Yellow line basic, IKA-WERKE, $415 \mathrm{~W}, 0-2000 \mathrm{rpm}$ ). Temperatures of up to $100{ }^{\circ} \mathrm{C}$ can be obtained with a fluctuation of $\pm 1^{\circ} \mathrm{C}$. Temperature at reactor inlet and outlet monitoring and recording is implemented with the use of $\mathrm{K}$ type thermocouples connected to a PC supplied with a system of continuous monitoring of analog inputs. Calibration of the Thermocouple-PC system was carried out by inserting the bimetallic thermocouple junction in a succession of water baths of known temperature (i.e. being varied preferably over the interval $30-60{ }^{\circ} \mathrm{C}$ and measured with a mercury thermometer) and by adjusting the parameters of the data acquisition system.

\section{Experimental Setup and Procedure}

- Flow sheet of apparatus

The flow sheet of the experimental setup, being employed for $\mathrm{H}_{2} \mathrm{~S}$ separation from a $\mathrm{H}_{2} \mathrm{~S}+\mathrm{N}_{2}$ mixture, is presented ín (Fig. 1). It is a semi-batch liquid recycle flow system comprised of a well stirred liquid storage vessel and a tubular wetted wall reactor vertically mounted at a point higher than that of the vessel. The reactor is designed to operate under differential $\mathrm{Fe}^{3+}$ conversion and laminar liquid flow regime. Liquid recycle from the well mixed vessel to the reactor top at a controlled flow rate was achieved by means of a pump. The liquid return to vessel is driven by gravity. In all runs, a continuous steady gas up-flow counter-currently to the liquid down-flow was applied.

\section{- Reactor}

The reactor, noted by $\mathrm{R}$ in Fig. 1 , is made up of a transparent plexiglass cylindrical tube (iner dia $d_{R i n}=24 \mathrm{~mm}$ and height $h_{R}=24 \mathrm{~cm}$, excluding the liquid inlet and outlet compartments) and a concentric glass rod (dia $d_{r}=0.8 \mathrm{~cm}$, wetted length in contact with the gas stream: $h_{w}=23.5$ $\mathrm{cm}$ ). The liquid entering the reactor top flows through an annular slit of $0.5 \mathrm{~mm}$ wide located between the rod and a concentric opening drilled through the flat bottom of the reactor top compartment. A falling liquid film is uniformly distributed over the rod surface being exposed to a counter current gas flow. For all applied temperature and $\mathrm{pH}$ conditions, the wetted rate was $\Gamma=1.4 \mathrm{~g} \mathrm{~s}^{-1} \mathrm{~cm}^{-1}$, (i.e. $\Gamma=u \rho / \pi d_{r}$ liquid mass flow rate per unit length of the wetted perimeter, where $u=3.33 \mathrm{~cm}^{3} \mathrm{~s}^{-1}$ liquid flow rate, $\rho=1.05 \mathrm{~g} \mathrm{~cm}^{-3}$ liquid density, $d_{\mathrm{ri}}=0.8 \mathrm{~cm}$, film thickness $\delta=\left(3 \mu \mathrm{u} / \pi g \mathrm{~d}_{\mathrm{r}} \rho\right)^{1 / 3}=0.0264-0.0316 \mathrm{~cm}$, liquid viscosity $\left.\mu=(4.78-8.17) 10^{-3} \mathrm{~g} \mathrm{~s}^{-1} \mathrm{~cm}^{-1}\right)$. Liquid phase Reynolds' number varied over the temperature range $30-60^{\circ} \mathrm{C}$ as follows: $\operatorname{Re}_{(1)}=$ $685-1170<1500$ (i.e. $\operatorname{Re}_{(1)}=4 \Gamma / \mu$, Bird et al. 2002) or $\operatorname{Re}_{(2)}=171-293<250-400$ (i.e. $\operatorname{Re}_{(2)}=\Gamma / \mu$, 
Danckwerts, 1970; Ammann et al., 2005). These values indicate that laminar flow conditions prevail in the liquid phase.

The Reynolds number for the gas flow in the annular space adjacent to the liquid film is estimated to be $\operatorname{Re}_{g} \approx 48<2200$ (i.e. $\operatorname{Re}_{(\mathrm{g})}=4 \Gamma_{\mathrm{g}} / \mu_{\mathrm{g}}=4\left(\mathrm{u}_{\mathrm{g}} \rho / \pi \mathrm{d}_{\mathrm{Rin}}\right) / \mu_{\mathrm{g}}$ where $\mathrm{U}_{\mathrm{g}}=17.17 \mathrm{~cm}^{3} \mathrm{~s}^{-1}, \rho_{\mathrm{g}}$ $=10^{-3} \mathrm{~g} \mathrm{~cm}^{-3}, \mathrm{~d}_{\text {Rin }}=2.4 \mathrm{~cm}$ and $\mu_{\mathrm{g}}=1.910^{-4} \mathrm{~g} \mathrm{~s}^{-1} \mathrm{~cm}^{-1}$ ) and is practically independent of the $\mathrm{pH}$ and temperature conditions. Such low $\mathrm{Re}_{(\mathrm{g})}$ values do not favor liquid surface rippling.

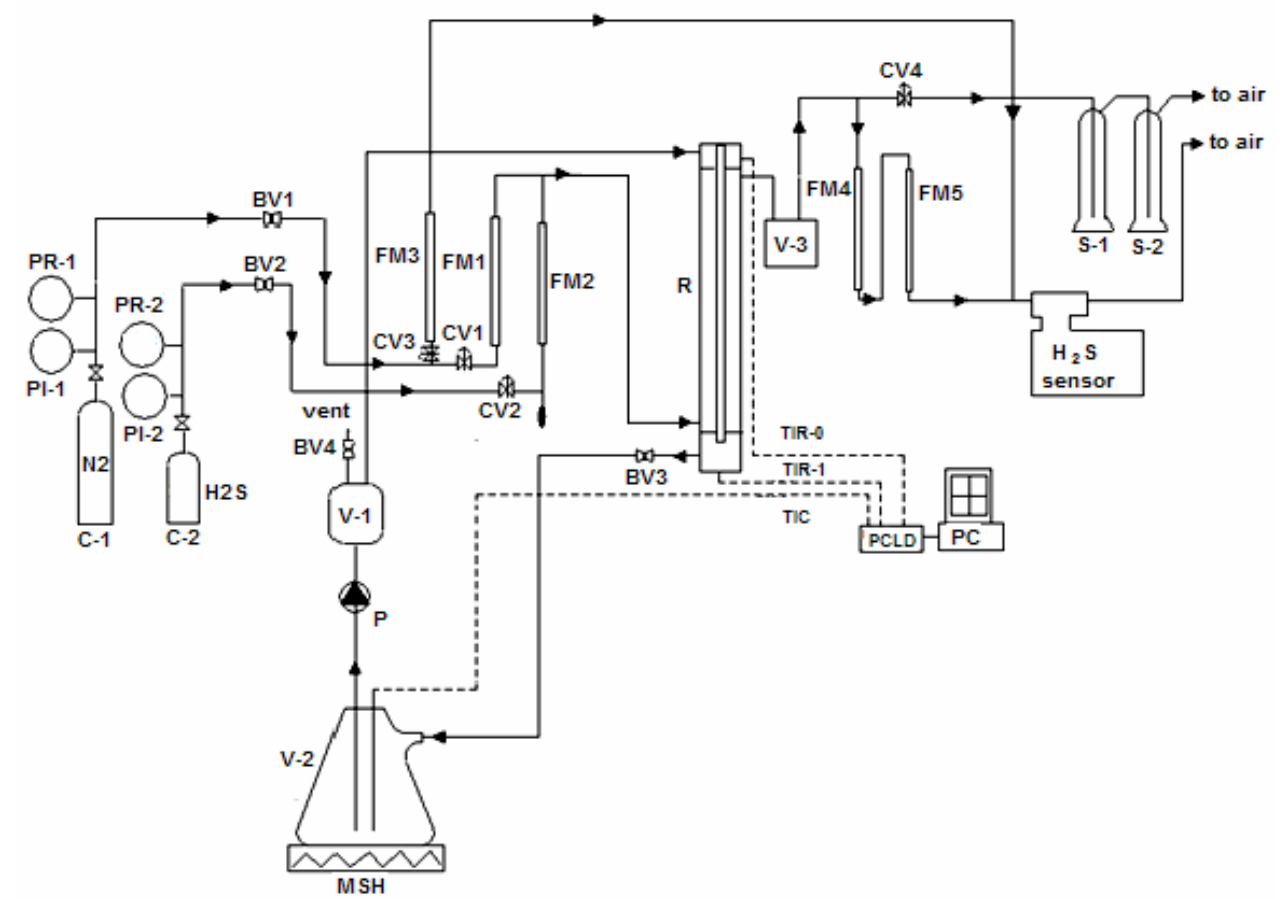

Figure 1. A semibatch recycle gas absorption experimental setup.

The iron chelate solution is charged in the tank and is being recycled through the wetted wall reactor during operation. A steady flow of the gas phase through the wetted wall reactor is maintained

(R) Gas/Liquid Falling Film Reactor, (C-1, C-2) $\mathrm{N}_{2}$ and $\mathrm{H}_{2} \mathrm{~S}$ Pressure Cylinders, (PI-1, PI-2) Feeding Gas Manometers, (PR-1, PR-2) Feeding Gas pressure regulator, (FM-1,FM-3) $\mathrm{N}_{2}$ Flowmeters, (FM-2) $\mathrm{H}_{2} \mathrm{~S}$ Soap Film Flowmeter, (FM-4, FM-5) Reactor outlet stream flowmeters (CV- 1, CV-2) Control Valves of Reactor Feed Streams, (CV-3) Control Valve of the $\mathrm{N}_{2}$ used for the sensor gas mixing, (CV-4) Control Valve of the Scrubber Feed Gas Stream, (BV1-BV4) Ball on-off valves, (P) Liquid Feed Peristaltic Pump, (V-1) Liquid Flow Pulse Dumping Vessel, (V-2) Thermoregulated Liquid Collection Vessel, (V-3) Liquid trap in the reactor effluent gas stream, (S-1) $\mathrm{H}_{2} \mathrm{~S}$ gas Scrubber (i.e. $20 \% \mathrm{NaOH}$ solution), (S-2) Auxiliary $\mathrm{H}_{2} \mathrm{~S}$ Gas Scrubber (i.e. $\mathrm{CdSO}_{4}$ solution), (TIR-0, TIR-1) Reactor Inlet-Outlet Temperature Indicator/Recorder, (TIC) Temperature Indicator/Controller of Liquid Collection Vessel, Hydrogen Sulphide Indicator TOX-PEM, (MSH) Magnetic stirrer-heater.

\section{- Typical absorption run}

The experimental procedure includes the following steps: (1) Charging the iron chelate solution, of known volume $\mathrm{V}_{\mathrm{L}}$ (Table 1) and initial chelate concentration, $\mathrm{C}_{\mathrm{Fe} 3+\mathrm{NTA}(0) \text {, (2) liquid }}$ heating up to the desired temperature, (3) establishing steady state flow of liquid recycle through the reactor (4) switching on the gas mixture (i.e. $\mathrm{H}_{2} \mathrm{~S}+\mathrm{N}_{2}$, of known composition) feeding through the reactor, counter-currently to the falling liquid film and (5) steady state operation until a conversion $\mathrm{x}_{\mathrm{Fe} 3+}=30 \%$, at the least, is reached. Three liquid samples at a time are collected from the liquid reservoir, at regular time intervals, and the $\mathrm{C}_{\mathrm{Fe} 3+\mathrm{NTA}(t)}$ is determined volumetrically. These values are practically equal to that in the reactor since the time lag between the liquid tank and the reactor is negligible $\left(\sim \mathrm{t}_{\text {lag }} \approx 15 \mathrm{~s}\right)$ and a differential $\mathrm{C}_{\mathrm{Fe} 3+}$ conversion of $0.01 \%$ occurs in the reactor. During an absorption run, systematic temperature monitoring and recording at reactor inlet and outlet, gas streams flow rate and liquid $\mathrm{pH}$ measurements are carried out. 


\section{RESULTS AND DISCUSSION}

Isothermal absorption runs were performed at controlled pressure, temperature and $\mathrm{pH}$ levels i.e. $\mathrm{P}=1 \mathrm{~atm}, \mathrm{~T}=30,40,50,60^{\circ} \mathrm{C}$ and $\mathrm{pH}=3,4,5,6$ (all possible combinations). Other applied operating conditions are: initial iron chelate concentrations and tank liquid load (given in Table 1), gas feed flow rates $U_{\mathrm{N} 2}=17$ and 1.02 and $U_{\mathrm{H} 2 \mathrm{~S}}=0.5 \mathrm{~cm}^{3} \mathrm{~s}^{-1}$, liquid recycle flow rate $\mathrm{U}_{\mathrm{L}}=3.33 \mathrm{~cm}^{3} \mathrm{~s}^{-1}$.

Table 1. Initial iron chelate concentration $\left(\mathrm{C}_{\mathrm{Fe} 3+\mathrm{NTA}(0)}\right)\left(\mathrm{mol} \mathrm{I}^{-1}\right)$ and tank liquid load $\mathrm{V}_{\mathrm{L}}(\mathrm{I})$, (within parenthesis) at the indicated temperature and $\mathrm{pH}$ values

\begin{tabular}{c|cccc} 
& \multicolumn{4}{|c}{$\mathrm{pH}$} \\
\hline $\mathrm{T}\left({ }^{\circ} \mathrm{C}\right)$ & 3 & 4 & 5 & 6 \\
\hline 30 & $0.102(1.86)$ & $0.103(1.85)$ & $0.100(1.80)$ & $0.100(1.87)$ \\
40 & $0.075(1.84)$ & $0.093(1.67)$ & $0.066(1.80)$ & $0.067(1.85)$ \\
50 & $0.095(1.85)$ & $0.087(1.85)$ & $0.090(1.85)$ & $0.091(1.83)$ \\
60 & $0.062(2.00)$ & $0.100(1.86)$ & $0.065(2.05)$ & $0.064(2.01)$
\end{tabular}

Original experimental data of relative concentration of $\mathrm{C}_{\mathrm{Fe} 3+\cdot \mathrm{NTA}} / \mathrm{C}_{\mathrm{Fe} 3+\cdot \mathrm{NTA}(0)}$ drop with processing time are depicted in Figure 2. It is readily seen in this figure that the $\mathrm{C}_{\mathrm{Fe} 3+}$ drop with time is linear, indicating a chemical kinetic equation $R_{H 2 S}=k C_{H 2 S}$, with $\left[R_{H 2 S}\right]=H_{2} S$ mole conver./(s $\cdot \mathrm{cm}^{3}$ of liquid). Dotted lines represent best straight line fit of data.

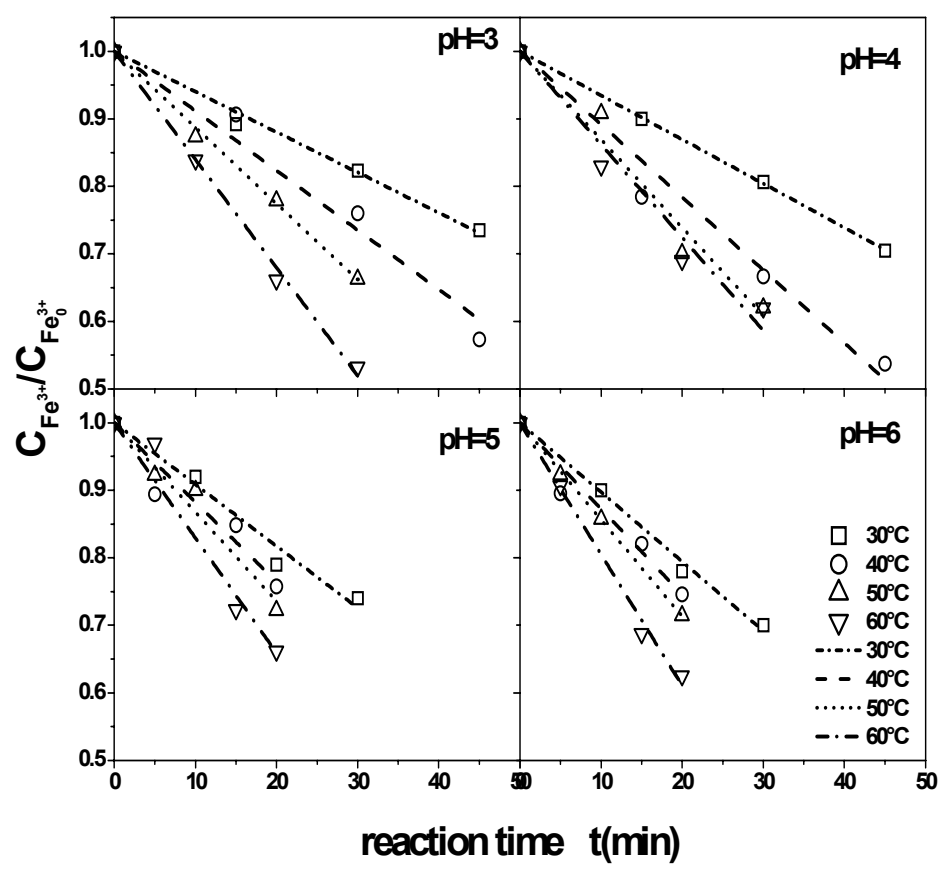

Figure 2. Relative iron chelate concentration drop vs the processing time,

i.e. $\mathrm{C}_{\mathrm{Fe} 3+\mathrm{NTA}(\mathrm{t})} / \mathrm{C}_{\mathrm{Fe} 3+\mathrm{NTA}(0)}$ vs $\mathrm{t}(\mathrm{min})$. Isothermal experimental runs at constant $\mathrm{pH}$.

Operating temperature and $\mathrm{pH}$ effects on absorption rate.

Absolute initial $\mathrm{C}_{\mathrm{Fe} 3+\mathrm{NTA}(0)}$ data are provided in Table 1.

Under steady state diffusion-reaction conditions the gas absorption rate $R_{\mathrm{H} 2 \mathrm{~S}}$ equals that of $\mathrm{H}_{2} \mathrm{~S}$ reacted according to the chemical reaction: $2 \mathrm{Fe}^{3+} \cdot \mathrm{NTA}+\mathrm{H}_{2} \mathrm{~S} \rightarrow 2 \mathrm{Fe}^{2+} \cdot \mathrm{NTA}+2 \mathrm{H}^{+}+\mathrm{S}$, then $R_{H 2 S(S)}=(1 / A)^{*}\left(V_{L} d C_{F e 3+N T A} / 2 d t\right)$, (moles $H_{2} S$ reacted $) /\left(s \cdot \mathrm{cm}^{2}\right.$ of $G / L$ interfacial area), where $V_{L}$ (I) liquid volume in the reservoir and $A\left(\mathrm{~cm}^{2}\right)$ the film interfacial area (i.e. $\left.A=\pi^{*}\left(d_{r}+2^{*} \delta\right)^{*} h_{w}\right)$. The $\mathrm{dC}_{\mathrm{Fe} 3+\mathrm{NTA}} / \mathrm{dt}$ derivative is evaluated from the slope of the relevant straight line of fig. 2 being multiplied by the respective initial iron concentration (data given in Table 1). For the applied $\mathrm{pH}$ and temperature conditions, the penetration theory for gas absorption with chemical reaction was employed for evaluating the enhancement factor $E$ (Fig. 3a) (Astarita, 
1966; Danckwerts, 1970; Sherwood et al., 1975). It is apparent from the latter figure that the chemical reaction causes the substantial acceleration of the $\mathrm{H}_{2} \mathrm{~S}$ absorption process especially at high $\mathrm{pH}$ and temperature values. $\mathrm{E}$ is calculated from the mean gas absorption rate per unit interfacial area, over the liquid residence time $\mathrm{T}$ in the reactor, i.e. $R_{H 2 S(S)}=k_{L}{ }^{0} C_{H 2 S}^{i} E$, for $C_{H 2 S}^{\text {bulk }}=0$ where $k_{L}{ }^{0}=2\left(D_{H 2 S} / \pi T\right)^{0.5}$ is the liquid phase $H_{2} S$ mass transfer coefficient for physical absorption and $\mathrm{C}_{\mathrm{H} 2 \mathrm{~S}}{ }_{\mathrm{S}}$ equilibrium gas concentration at the $\mathrm{G} / \mathrm{L}$ interface calculated from $\mathrm{C}_{\mathrm{H} 2 \mathrm{~S}}^{i}=\mathrm{Py}_{\mathrm{H} 2 \mathrm{~S}} / \mathrm{He}=\mathrm{P}\left(\mathrm{y}_{\mathrm{H} 2 \mathrm{~S}}\right)_{\text {bulk }} / \mathrm{He}$, for negligible gas phase $\mathrm{H}_{2} \mathrm{~S}$ diffusion resistance.

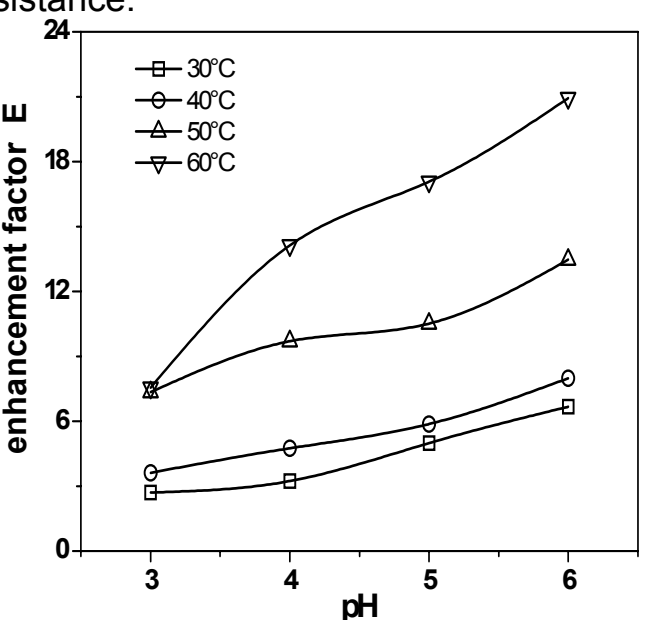

Figure 3 (a). Enhancement factor dependence on operating $\mathrm{pH}$ and temperature for the $\mathrm{H}_{2} \mathrm{~S}$ oxidation process

$\begin{array}{lll}\text { - } & \mathrm{pH}=3 \operatorname{In}(\mathrm{k})=-9018.5^{*}(1 / \mathrm{T})+31.371 & \mathrm{E}_{\mathrm{a}}=17.9 \\ \text { } & \mathrm{pH}=4 \operatorname{In}(\mathrm{k})=-11488^{*}(1 / \mathrm{T})+39.866 & \mathrm{E}_{\mathrm{a}}=22.8 \\ \text { (. } & \mathrm{pH}=5 \operatorname{In}(\mathrm{k})=-9396.4^{*}(1 / \mathrm{T})+33.770 & \mathrm{E}_{\mathrm{a}}=18.0 \\ \text { - } & \mathrm{pH}=6 \ln (\mathrm{k})=-8661.3^{*}(1 / \mathrm{T})+31.995 & \mathrm{E}_{\mathrm{a}}=17.2\end{array}$

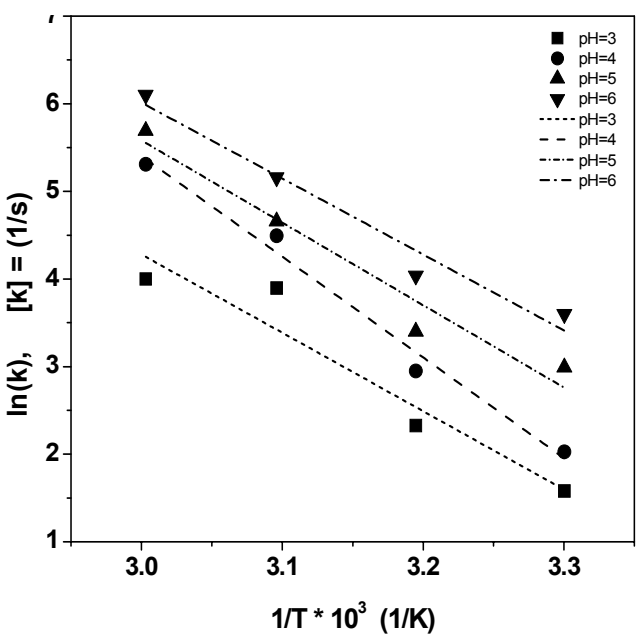

Figure 3 (b). Arrhenius plots for the oxidation of $\mathrm{H}_{2} \mathrm{~S}$ in aqueous solutions of $\mathrm{Fe}^{3+}$ (NTA) at the specified $\mathrm{pH}$. From the best straight line

fit the following specific reaction rate constant correlations and activation energies $\left(\mathrm{E}_{\mathrm{a}}, \mathrm{kcal} \mathrm{mol}^{-1}\right)$, were obtained

To validate the latter assumption the following results were obtained by applying the Gilliland correlation for diffusion of vapors in air streams (eq. 6.11, in Sherwood et al., 1975; Gilliland and Sherwood, 1934), i.e. $\left(k_{c} d_{R i} P_{B M}\right) /\left(D_{A B} P\right)=0.023 R{ }_{g}^{0.83} S^{0.44}$, where $k_{c}$ is $H_{2} S$ gas phase mass transfer coefficient, calculated to be $k_{C}=0.044 \mathrm{~cm} \mathrm{~s}^{-1}, P$ and $P_{B M}$ total gas pressure and logarithmic mean $N_{2}$ partial pressure in the reactor respectively, $D_{A B}$ is the $H_{2} S / N_{2}$ gas phase binary molecular diffusion coefficient, $D_{A B}=0.1715 \mathrm{~cm}^{2} \mathrm{~s}^{-1}$ (eq. 2.22, in Sherwood et al. (1975), at $\mathrm{T}=303 \mathrm{~K}, \mathrm{P}=1 \mathrm{~atm}), \mathrm{Re}_{\mathrm{g}}=48, \mathrm{Sc}=\mu_{\mathrm{g}} / \rho_{\mathrm{g}} \mathrm{D}_{\mathrm{AB}}=1.910^{-4} /\left(10^{-3} 0.1715\right)=1.108$. Under steady state diffusion-reaction conditions the relation $\mathrm{R}_{\mathrm{H} 2 \mathrm{~S}(\mathrm{~S})}=\mathrm{k}_{\mathrm{C}}\left(\mathrm{C}_{\mathrm{H} 2 \mathrm{~S}(\mathrm{~g} \text { bulk })}-\mathrm{C}_{\mathrm{H} 2 \mathrm{~S}(\mathrm{i})}\right)=\mathrm{k}_{\mathrm{cp}}\left(\mathrm{P}_{\mathrm{H} 2 \mathrm{~S}(\text { bulk })^{-}}\right.$ $\mathrm{P}_{\mathrm{H} 2 \mathrm{~s}(\mathrm{i})}$ ) (where $\mathrm{k}_{\mathrm{cp}}=\mathrm{k}_{\mathrm{c}} / \mathrm{RT}$ and $\mathrm{k}_{\mathrm{cp}}=1.7710^{-6} \mathrm{~mol} \mathrm{~s}^{-1} \mathrm{~cm}^{-2} \mathrm{~atm}^{-1}$ for $\mathrm{pH}=3$ and $\mathrm{T}=303 \mathrm{~K}$ ), holds

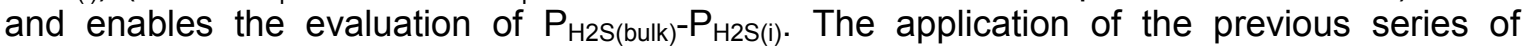
calculations for various $\mathrm{pH}$ and temperature conditions yielded ca. $0.4 \%<100\left(\mathrm{P}_{\mathrm{H} 2 \mathrm{~S}(\mathrm{bulk})}\right)^{-}$ $\left.\left.\left.\mathrm{P}_{\mathrm{H} 2 \mathrm{~S}(\mathrm{i})}\right) / \mathrm{P}_{\mathrm{H} 2 \mathrm{~S}(\text { bulk) })}\right)<1 \%\right)$ ) confirming a negligible $\mathrm{H}_{2} \mathrm{~S}$ gas phase diffusion resistance.

Intrinsic reaction rate constant $\mathrm{k}\left(\mathrm{s}^{-1}\right)$ values were computed from: $\mathrm{y}=\mathrm{Ha}=\left(1 / \mathrm{k}_{\mathrm{L}}{ }^{0}\right)\left(\mathrm{kD}_{\mathrm{H} 2 \mathrm{~S}}\right)^{0.5}$ where $\gamma$ is evaluated from: $E=(\gamma+\pi / 8 \gamma)^{*} \operatorname{erf}\left(2 \gamma / \pi^{0.5}\right)+0.5^{*} \exp (-4 \gamma / \pi)$. Numerical data for $k$ are plotted against the reciprocal of temperature in $\mathrm{K}$ (Arrhenius plots of Figs.3b and $4 \mathrm{a}$ ). Activation energy values were derived from a linear fit. From the unified Arrhenius diagram of fig. $4 a$ an average activation energy $E a=19.1 \mathrm{kcal}^{\mathrm{mole}}{ }^{-1}$ was deduced. The latter value indicates that the overall phenomenon is controlled by the chemical reaction.

As illustrated in Fig. 4b, a linear dependence of the frequency factor of the specific kinetic constant upon $\mathrm{pH}$, was confirmed. The kinetic equation (eq. 1) for $\mathrm{H}_{2} \mathrm{~S}$ selective oxidation into $\mathrm{S}$, in aqueous solutions of $\mathrm{Fe}^{3+}$ (NTA) was validated.

$$
R_{H 2 S}=\left\{[-10.62+4.15(p H)] \cdot 10^{14} \exp \left(-19083 / R_{g} T\right)\right\} C_{H 2 S}
$$




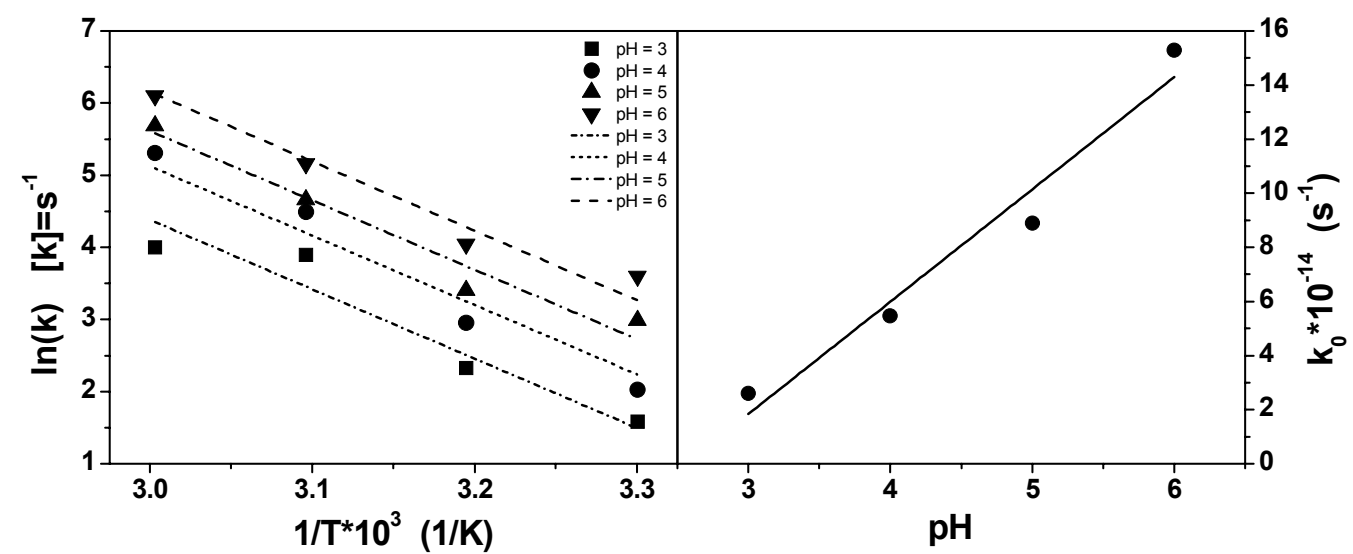

Figure 4 (a). Unified Arrhenius plots for $\mathrm{H}_{2} \mathrm{~S}$ oxidation in $\mathrm{Fe}^{3+}$ (NTA) aqueous solutions at the specified $\mathrm{pH}$. A constrained, constant slope, straight line fit yielded a single 'mean' activation energy of Ea=19.1 kcal mol ${ }^{-1}$

Figure 4 (b). Dependence of the Arrhenius frequency factor $\mathrm{k}_{0}$ of the specific kinetic constant upon $\mathrm{pH}$. The best straight line fit correlation for the frequency factor is: $\mathrm{k}_{0}=[-10.62+4.15 \cdot \mathrm{pH}] 10^{-14} \mathrm{~s}^{-1}$

It should be mentioned that the kinetic correlation (eq. 1) is based on $\mathrm{C}_{\mathrm{Fe} 3+}$ conversion data obtained for batch-recycle operating time up to $30 \mathrm{~min}$, and for an initial $\mathrm{C}_{\mathrm{Fe} 3+} \leq 0.100 \mathrm{gmol} \mathrm{I}^{-1}$. Under these conditions, the measured $\mathrm{Fe}^{3+}$ conversion rate represents an initial reaction rate with minimal influence from the presence of sulfur particulates. The kinetic order for both $\mathrm{C}_{\mathrm{H} 2 \mathrm{~S}}$ and $\mathrm{C}_{\mathrm{Fe} 3+}$ may be different for longer batch-recycle operating time where an appreciable amount of sulfur might be present. Other aspect that would alter the proposed kinetics may be related to the presence of ligand degradation by-products if regenerated $\mathrm{Fe}^{2+}$ (NTA) solution are to be used for successive $\mathrm{H}_{2} \mathrm{~S}$ oxidations.

\section{CONCLUSIONS}

Under short reaction time and in the presence of negligible amount of sulfur product, the oxidation reaction of hydrogen sulfide in aqueous solutions of $\mathrm{Fe}^{3+}$ occurs at a finite rate with kinetics of zero order with respect to $\mathrm{Fe}^{3+}$ and first order with respect to $\mathrm{H}_{2} \mathrm{~S}$ concentrations. For the $\mathrm{pH}$, temperature and initial $\mathrm{Fe}^{3+} \mathrm{NTA}$ chelate concentration ranges investigated the overall absorption phenomenon is chemical reaction controlled with an activation energy ca. $\mathrm{Ea}=19 \mathrm{kcal} \mathrm{mole}^{-1}$. This value approach the corresponding value Ea=24 kcal mole ${ }^{-1}$ obtained from a bubble column reactor (Pitsinis and Androutsopoulos, 1997). However, in the present case the enhancement factor is certainly higher. The results obtained ín the present study are superior in comparison with relevant literature data since they apply to wide $\mathrm{pH}$ and temperature ranges. Further studies combining longer reaction times and the use of regenerated $\mathrm{Fe}^{3+}$ NTA solutions are required to develop a more general kinetic correlation reflecting the influence of side reaction and particularly the presence of chelant degradation by-products.

\section{LIST OF SYMBOLS}

$\mathrm{C}_{\mathrm{H}_{2} \mathrm{~S}}^{i}$ hydrogen sulfide equilibrium concentration on gas-liquid interface $\left.(\mathrm{mol} \mathrm{cm})^{-3}\right)$.

$\mathrm{C}_{\mathrm{Fe}+\mathrm{NTA}(\mathrm{t})}$ initial iron chelate concentration at absorption time $\mathrm{t},\left(\mathrm{mol} \mathrm{cm}^{-3}\right)$.

$D_{\mathrm{H} 2 \mathrm{~S}}$ liquid phase hydrogen sulfide diffusion coefficient $\left(\mathrm{cm}^{2} \mathrm{~s}^{-1}\right)$ (Eq. 2.28, Sherwood et al., 1975).

$\mathrm{Ha} \quad$ Hatta number

$\mathrm{He} \quad$ Henry coefficient (atm mol solution $\mathrm{mol}^{-1}$ solute)

Sc Schmidt Number in gas phase $\left(\mu_{g} / \rho_{g} D_{A B}\right)$

$u_{a v} \quad$ average liquid velocity $u_{a v}=\rho g \delta^{2} / 3 \mu=41.9-50.1\left(\mathrm{~cm} \mathrm{~s}^{-1}\right)$, over the film thickness $\delta$ (mean value over the film hight $h_{w}$ ).

$u_{s} \quad$ surface liquid velocity, $u_{s}=(3 / 2)\left(u / \pi d_{r}\right)^{2 / 3}(\rho g / 3 \mu)^{1 / 3}=62.9-75.3 \mathrm{~cm} / \mathrm{s}$, (mean value over the film hight $h_{w}$ ). 
$\left(\mathrm{y}_{\mathrm{H} 2 \mathrm{~S}}\right)_{\text {bulk }} \mathrm{H}_{2} \mathrm{~S}$ molar fraction in gas bulk.

$\mathrm{y}_{\mathrm{H} 2 \mathrm{~S}}^{\mathrm{i}}$ equilibrium $\mathrm{H}_{2} \mathrm{~S}$ molar fraction on gas-liquid interface.

$\mathrm{T}$ contact time of phases on liquid film surface, $\mathrm{T}=\mathrm{h}_{\mathrm{w}} / \mathrm{u}_{\mathrm{s}},=0.31-0.37 \mathrm{~s}$.

\section{REFERENCES}

Ammann M., Rössler E., Strekowski R., George Ch., (2005), Nitrogen Dioxide Multiphase Chemistry: Uptake Kinetics on Aqueous Solutions Containing Phenolic Compounds, Phys. Chem. Chem. Phys., 7, 2513-2518.

Astarita G., (1966), Mass Transfer with Chemical Reaction, Elsevier, Amsterdam.

Bedell S.A., Kirby L.H., Buenger C.W., McGauge M.C., (1988), Chelates' role in gas treating, Hydrocarbon Processing, 1, 63-66.

Bird R.B., Stewart W.E., Lightfoot E.N., Transport Phenomena, John Wiley \& Sons Inc., $2^{\text {nd }}$ Ed. (2002).

Caruana C.M., (1996) Processes Aim to Improve Sulfur Recovery from Gases, Chem. Eng. Progress, 92, 1- 17.

Chevron U.S.A. Production Co.,(1996), Steamflood Expansion Includes Liquid Redox Process, Oíl and Gas Journal, $29,99$.

Danckwerts P.V. (1970), Gas-Liquid Reactions, McGraw - Hill 34, 193, 113.

Demmink J.F., Wubs H.J., Beenackers A.A.C.M., (1994), Oxidative Absorption of Hydrogen Sulfide by a Solution of Ferric Nitilotriacetic Acid Complex in a Cocurrent Down Flow Column Packed with SMV - 4 Static Mixers, Ind. Eng. Chem. Res., 33, $2989-2995$.

Hardison L.C. (1985), Go from H2S to $S$ in one Unit, Hydrocarbon Processing, 4. $70-71$.

Gilliland E.R., Sherwood T.K., (1934), Diffusion of Vapors into Air Streams, Ind. Eng. Cmem., 26(5), 516-523.

Heisel M.P., Marold F.J., (1987), New Gas Scrubber Removes $\mathrm{H}_{2} \mathrm{~S}$, Hydrocarbon Processing, April, 35-37.

Hua G.X., Mc-Manus D., Woollins J.D., (2001), The Evolution, Chemistry and Applications of Homogeneous Liquid Redox Sulfur Recovery Techniques, Comments on Inorganic Chemistry, 22(5), 327-351.

Hua G.X., Zhang Q., McManus D., Slawin A.M.Z., Woollins J.D., (2005), Novel Aqueous Chelating Agents for Catalytic Oxidation of Hydrogen Sulfide to Sulfur by Air, Main Group Chemistry, $\mathbf{4}$ 157-175.

Kohl A.L., Nielsen R.B., (1997), Gas Purification, Gulf Publishing Company, Fifth Edition, Houston, Texas.

Newmann D.W. and Lynn S., (1984), Oxidative Absorption of $\mathrm{H}_{2} \mathrm{~S}$ and $\mathrm{O}_{2}$ by Iron Chelate Solutions, AlChE Journal, 30(1), 62-69.

Pagella,C., De-Faveri D.M., (2000) $\mathrm{H}_{2} \mathrm{~S}$ Gas Treatment by Iron Bioprocess, Chem. Eng. Sci., 55, 2185-2194.

Pitsinis N., Androutsopoulos G. (1997), 1st Panhellenic Conference of Chemical Engineer, University of Patra, Proc.383 - 388.

Sherwood, T.K., Pigford, R.L., Wilke, C.R., (1975), Mass Transfer, Mc Graw Hill, New York.

Smith K.L., Smoot L.D., Fletcher T.H., Pugmire R.J., (1994), The Structure and Reaction Properties of Coal, Plenum Press, New York.

Speight J.G. (Ed.), (1990), Fuel Science and Technology Handbook, New York, Marcel Dekker. 